\title{
Esthetic Replacement of Composite Veneers by Lithium Disilicate (E.Max CAD) Based Crowns: A Case Report
}

\begin{abstract}
Albinali Abdullatif*
Department of Restorative dentistry, Aseer Specialist Dental Center, Kingdom of Saudi
\end{abstract} Arabia

*Corresponding author: Abdullatif Albinali, Senior registrar, Department of

\author{
Case Report \\ Volume 4 Issue 2 \\ Received Date: April 08, 2019 \\ Published Date: April 15, 2019 \\ DOI: $10.23880 /$ oajds-16000223
}

Restorative dentistry, Aseer Specialist Dental Center, Abha, Kingdom of Saudi Arabia, Email: latif626@yahoo.com

\section{Abstract}

This case report highlights the rehabilitation of aesthetic smile by Lithium Disilicate (IPS e.max CAD) ceramic crowns of all upper anterior teeth that were compromised due to previous defective old composite veneers with poor color and design in esthetic zone.

Keywords: Composite veneers; Esthetic; Lithium Disilicate; CAD/CAM

\section{Introduction}

The concept of no-preparation or minimal-preparation [1] followed the development of appropriate enamel bonding procedures. Direct restoration of missing dental tissue with composite resin has advantages such as minimally invasive, low cost compared with indirect techniques and other prosthetic approaches, reversibility, and a relatively simple technique, easy to repair (cracks or fractures 8), easy Intraoral polishing [2,3] and no need for an additional adhesive cementing system are some advantages of this technique [4,5]. Composite materials have increased conservative treatments of compromised anterior teeth [6,7]. The main indications for direct laminate veneer restorations are tooth discolorations, rotated teeth, coronal fractures, congenital or acquired malformations, diastemas, discolored restorations, palatally positioned teeth, absence of lateral incisors, abrasions and erosions are [8,9] however, for extensive tooth reconstruction, composites have a high failure rate, [10] averaging $2.9 \%$ annually. This can be due to secondary caries, loss of restoration, pigment impregnation, fracture, marginal defects [11] or a high degree of color instability [12]. The mechanisms behind the development of SC are much less clear and are most probably multifactorial (gaps and microleakage).

Rehabilitation should include not only the esthetic aspect but also the reestablishment of occlusion, such as anterior and lateral guidance. Excellent soft tissue health and correct tooth contours and emergence profiles are just as important as the actual color of the new restoration/adjacent teeth $[13,14]$. All-ceramic crowns have been used over the last four decades not only as solution to a failure of laminate veneers but also as an alternative for porcelain-fused-to-metal crowns to overcome their esthetic disadvantages especially in esthetic zone.

\section{Case Report}

A 44-year-old female patient was referred to the clinical concerned about her smile, her chief complaint was that (I don't like the appearance of my front teeth) she was not happy with her previous treatment (Figure 1). 


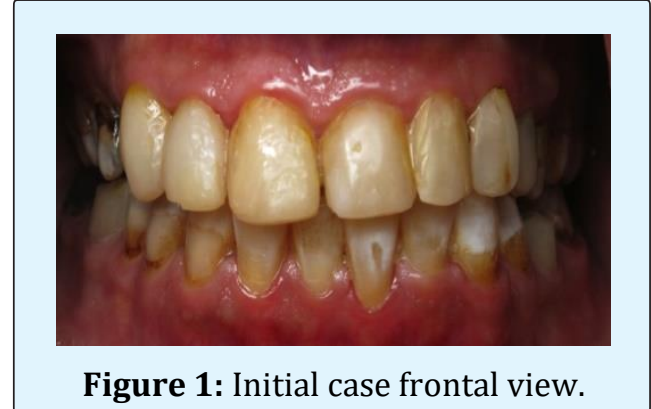

The clinical examination and history revealed that the patient was within normal ranges. Clinical and radiographic examinations showed (Figure 2) old composite veneer restorations of all upper anterior teeth, secondary caries were detected at the mesial and distal surfaces of maxillary central lateral incisors and canines of the patient (Figure 2). There was also a discrepancy in the width and length of the central Incisors, poor adaptation and polishing of composite (Figure 3).

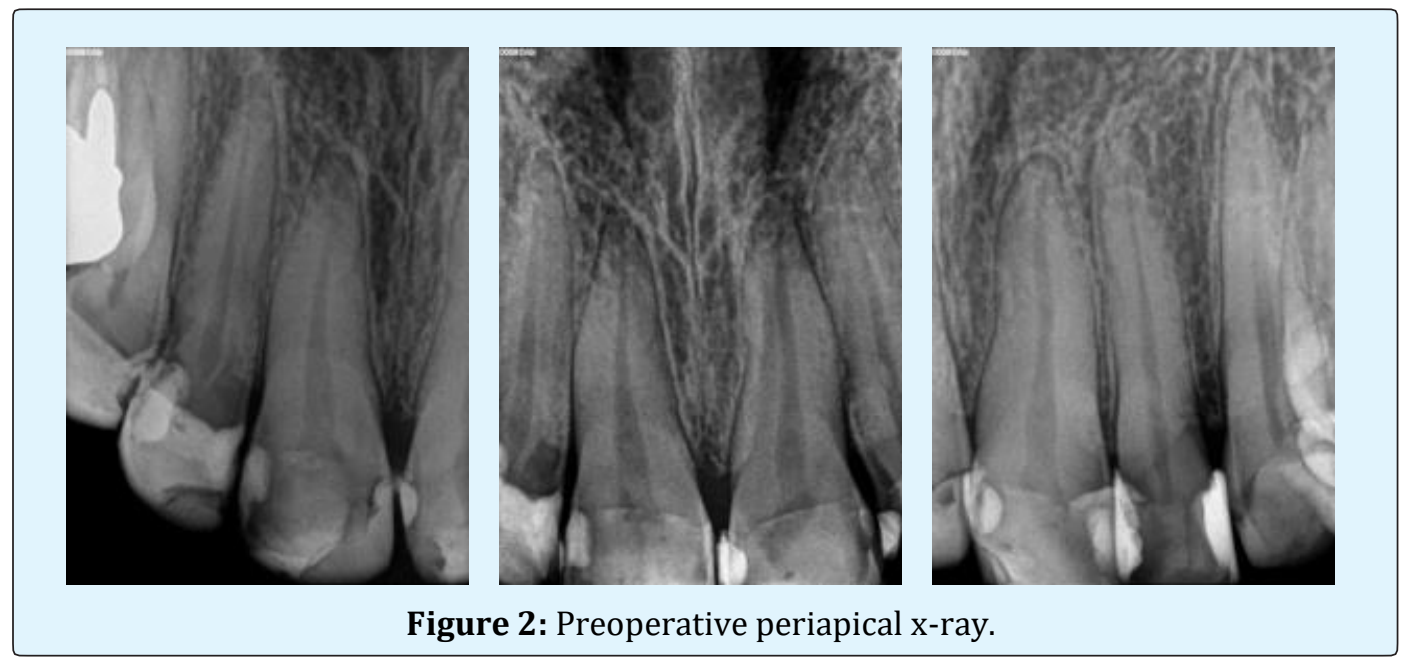

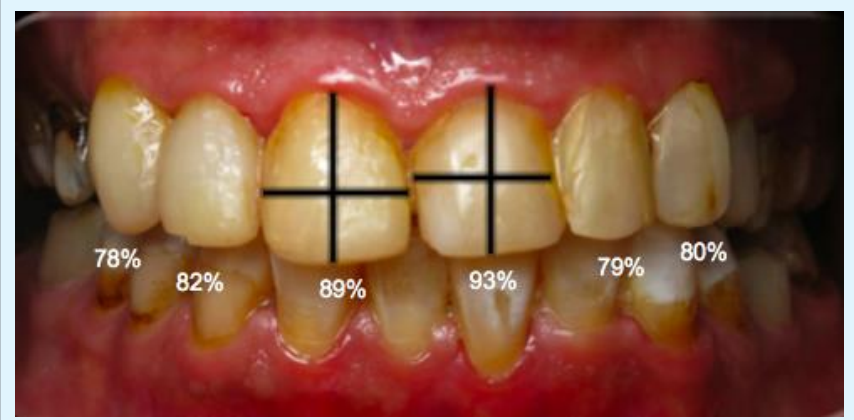

Figure 3: Initial case showing discrepancy in the width and length of the central Incisors.

According to the patient's history, the composite veneer restorations were about four years old and performed as an esthetic treatment because of her fluorosed anterior teeth. After proper clinical examination, complete review and analyze of the patient's socioeconomic status, esthetic expectations and oral hygiene conditions, the dentist has to make the decision to obtain a correct indication. Esthetic rehabilitation with glass ceramic lithium disilicate (emax CAD, Ivoclar Vivadent) as all ceramic esthetic for maxillary central incisors and canines was planned, thanks to their more tooth-like appearance and sufficient strength. During the first appointment a silicone primary impression was taken for the preliminary wax-up .The models were mounted on a semi adjustable articulator (Figure 4).

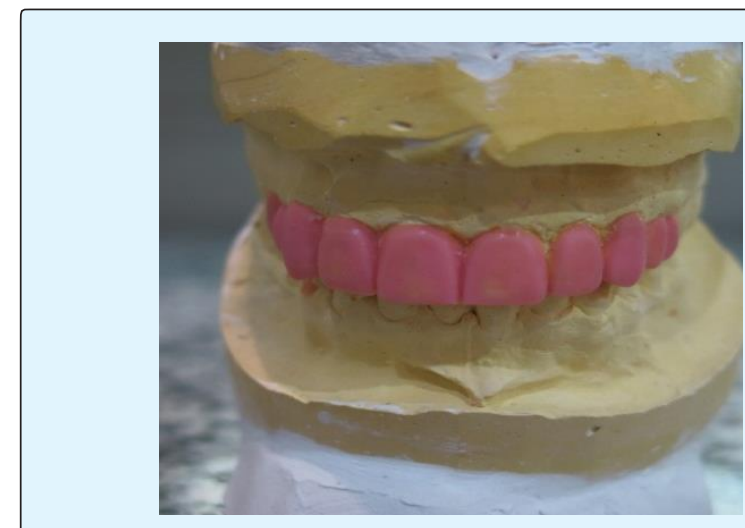

Figure 4: Mounted diagnostic wax-up on articulator for final diagnostic appearance.

Two putty indexes were made; one was used to verify the proper reduction. The other was used to perform interim crowns. 
The treatment protocol should be as conservative as possible with less reduction of teeth structure and greater esthetics and longevity [15]. The shade of maxillary teeth was selected as $1 \mathrm{M} 1$ using Vita 3D master. The preparations were performed respecting the shared preparation principles in the anterior regions for all systems (i.e., single-unit and FPD abutment) include an incisal reduction of $1.5 \mathrm{~mm}$ to $2 \mathrm{~mm}$ with diamond burs for incisors canines and finish line for each tooth was a deep chamfer [16]. During preparation of anterior teeth the carious lesions were removed (Figure 4) and direct composite restorations were performed (Figure 5). There was a large amount of lost tooth structure due to secondary caries and great care should be taken during caries excavation to ovoid pulp exposure, which will need a root canal treatment and may change the treatment procedure.

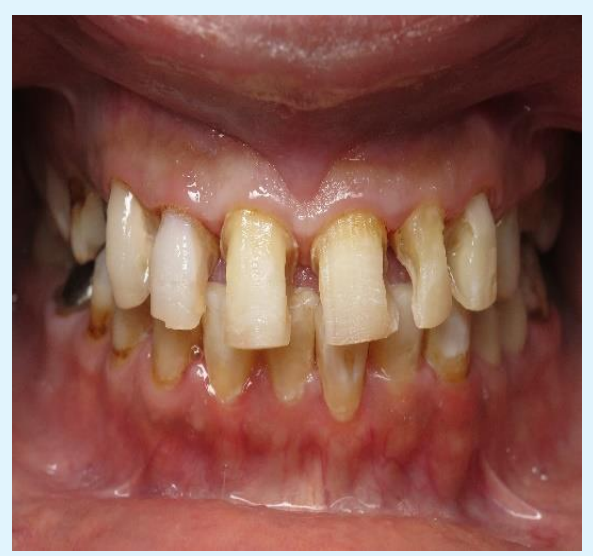

Figure 4: Initial preparation and caries removal.

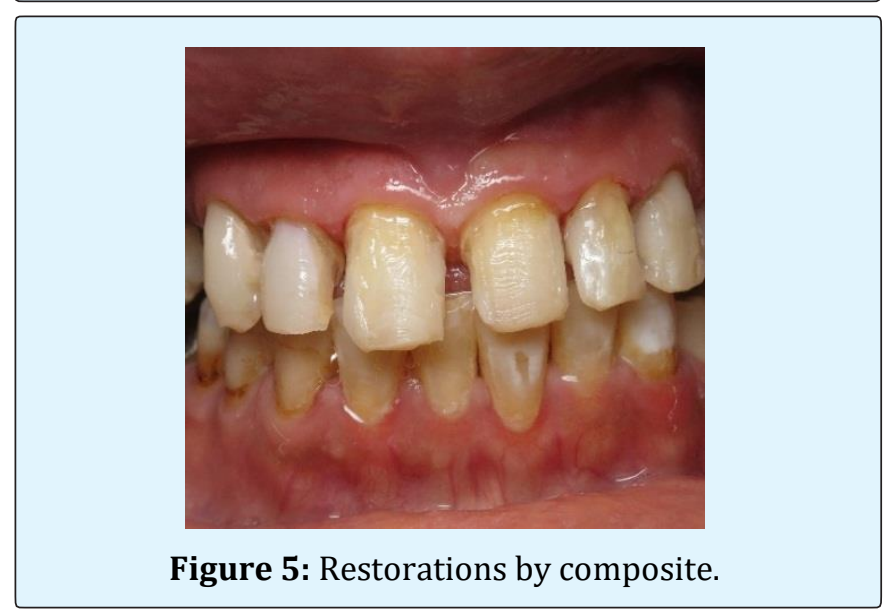

Provisional restorations were made by an index using bis-acryl resin (Protemp). Most CAD/CAM systems recommend that the minimum axial wall reduction for anterior crowns should be $1 \mathrm{~mm}$ to $1.5 \mathrm{~mm}$. The total occlusal convergence angle can range between $4^{\circ}$ to $6^{\circ}$ (Figure 6). Finishing and polishing of preparation of the teeth were performed with diamond points using a speed multiplier (W \& H Dentalwerk, Bürmoos, Austria).

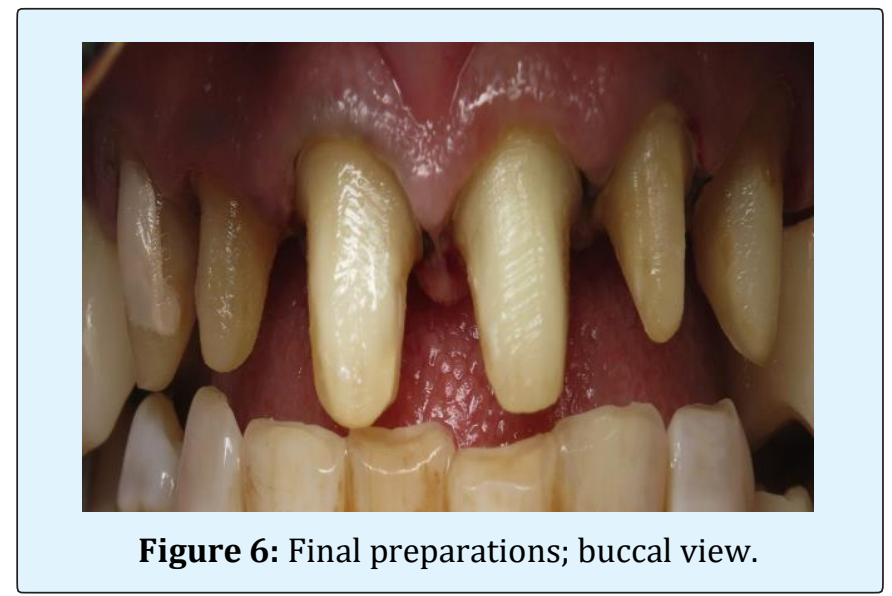

On another hand Provisional restorations were made by an index using bis-acryl resin (Protemp) (Figures 7,8) and cemented with temporary free eugenol cement. They were used as prototype to assess esthetic, phonation and occlusal scheme of patient they were also well accepted by the patient.

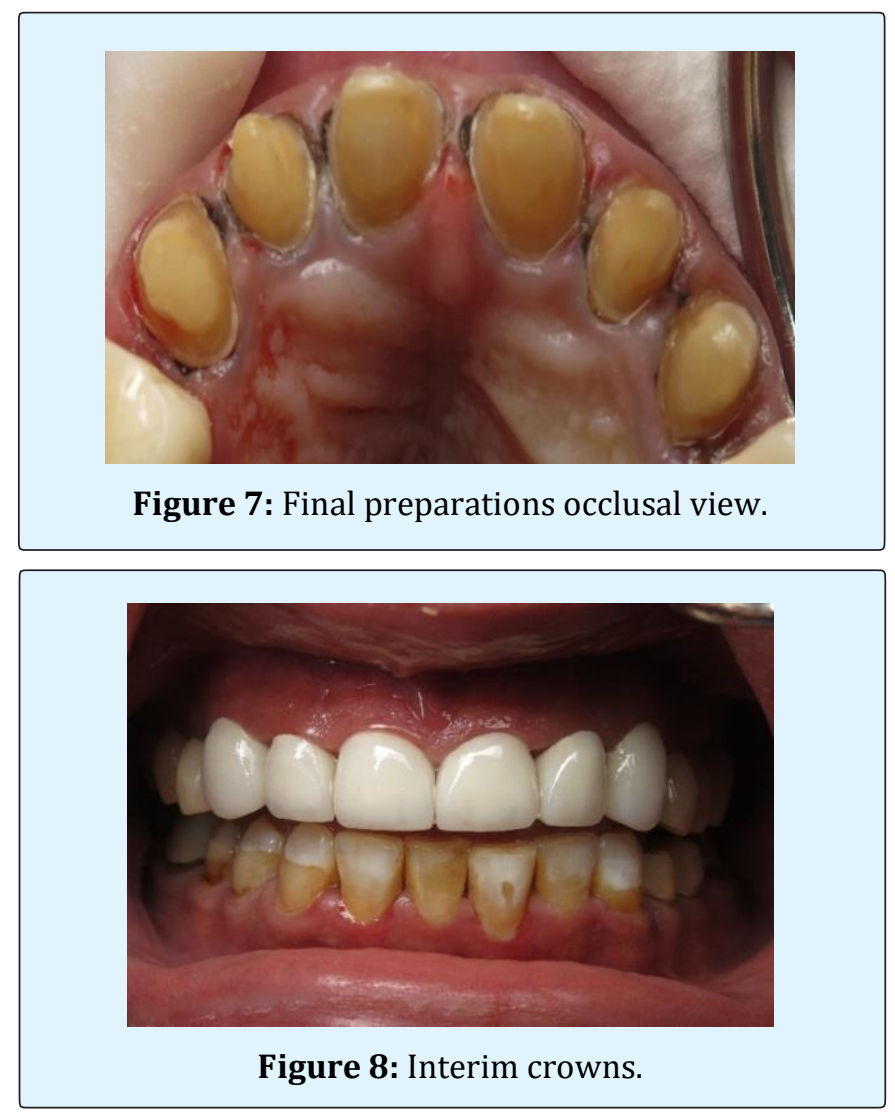




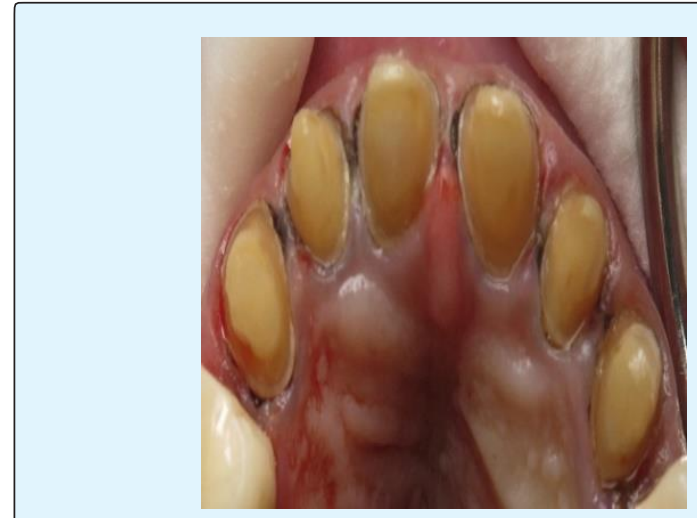

Figure 9: Gingival retraction using impression.

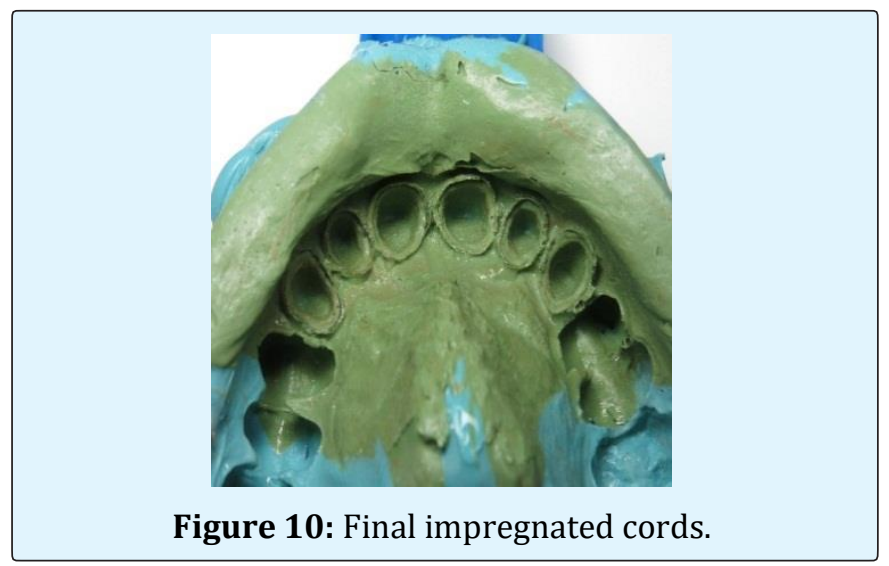

After gingival retraction carried out using an impregnated cord (Figure 9) a final impression was taken using polyvinyl siloxane (Virtual, Ivoclar Vivadent) (Figure 10) and sent to the laboratory.

After scanning the working cast, frameworks were manufactured with computer-assisted design computeraided manufacturing using indirect technique. In the clinic they were tried in the mouth to asses marginal fit, stability, and the space left for ceramic cosmetic. A bite wing was useful to check proximal fit.

Beforehand correct path of insertion of the 6 crowns should be clearly determined to allow an accurate crown seating in the arch during cementation. In the clinic, after ceramic stratification in the lab, esthetic and static and functional occlusion were checked, and crowns were sent again to the lab for glazing. The abutments were cleaned to remove the temporary cement which can jeopardize not only the precision of seating, but also the optimal bonding of the glace ceramic crowns. The inner surfaces of the disilicate crowns were etched with $10 \%$ of hydrofluoric acid for 1.5 minutes and dried, then a coat of silane coupling agent was applied for 1 minute [17]. The cementation was carried out with a dual cure luting agent Rely X U 200(3M ESPE) using the quarter technique (Figures $11 \& 12$ ).

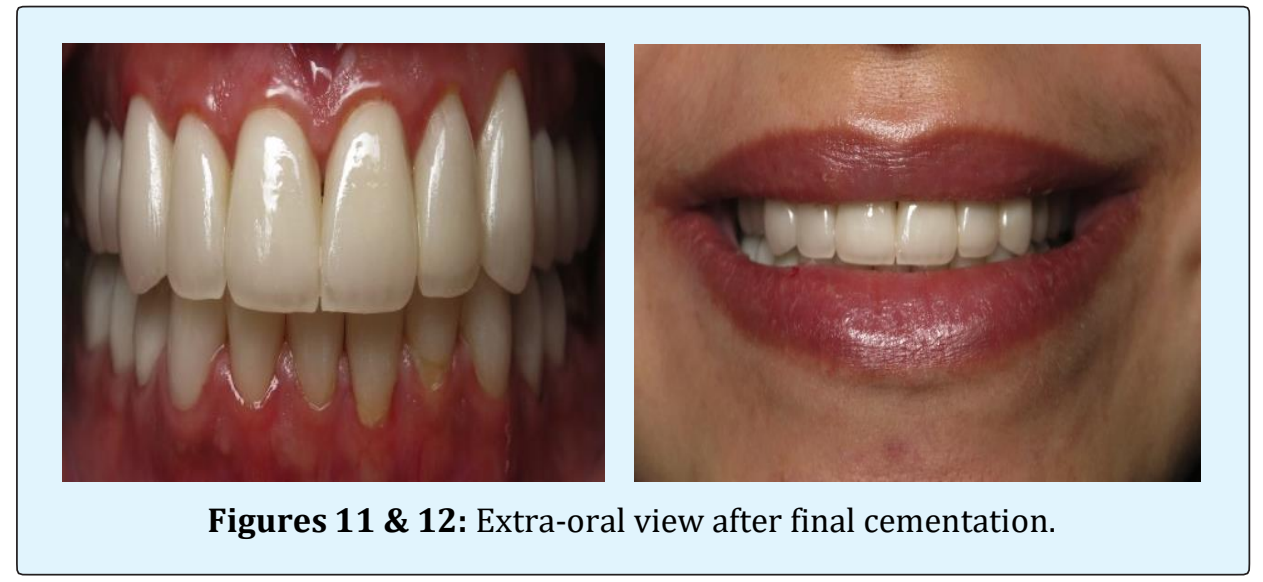

The patient was instructed in oral hygiene and was scheduled for control appointments once every 6 months.

\section{Discussion}

A number of clinical studies have concluded that bonded laminate veneer restorations delivered good results over a period of 10 years and more $[18,19]$. The majority of the failures were observed in the form of fracture or marginal defects of the restoration [20]. The main disadvantages of direct laminate veneers are low resistance to wear, discoloration and fractures [9,4,21] and secondary caries. The patient-related factors (caries risk profiles) remain the most important determinant of secondary caries. The other causes are more likely due to gap originate through polymerization shrinkage and 


\section{Open Access Journal of Dental Sciences}

through the technique-sensitive placement procedure [22]. Faulty restorations as well as Proximal and extensive tooth decay exclude the indication of composite or ceramic laminate veneers in favor of all ceramic crowns.

In our case there was a large amount of loss of tooth structure due to secondary caries and great care should be taken during caries excavation to ovoid pulp exposure which will need a root canal treatment and may change or complicate the treatment procedure. Treatments of fluorosis include microabrasion, direct composite restorations, esthetic veneers or crowns or combination of the above mentioned techniques [23]. Bonding procedure to the fluorosed enamel and dentin can be challenging. Some modifications in the preparation etching time and selection of adhesive system had been done [24-26] in the mild or moderate cases of fluorosis [27]. The best etching result were obtained at 30 seconds for the moderate fluorosed enamel. Etch-and-rinse systems provide the highest bond strength to fluorosed enamel $[28,29]$.

Restoring translucency to the incisal edge was obtained with optical effects, such as color opalescence, and translucency of emax CAD. The CAD/CAM technique used in this clinical case has a predictable outcome and less time consuming than the pressing technique (wax lost technique). Glace ceramics as Ips emax CAD are biocompatible restorative materials that improve periodontal health in the long term due to their surface smoothness.

\section{Conclusion}

Glace ceramic crowns, as full-coverages, constitute an alternative to composite laminate veneers restorations related to a failure caused by a discoloration and recurrent caries. They are a suitable solution in case of discoloration and supragingival tooth decay .They enabled to reestablish a like life esthetic smile, periodontal health, occlusion and long life lasting.

Acknowledgment: The author expresses his deep appreciation to Doctor Jilani Saafi, Professor in fixed prosthodontics at the faculty of dentistry of Monastir (Tunisia) for the great help and generous support in preparing this case report.

\section{References}

1. Magne P, Hanna J, Magne M (2013) The case for moderate, "guided prep" indirect porcelain veneers in the anterior dentition. The pendulum of porcelain veneer preparations: from almost no-prep to overprep to no-prep. Eur J Esthet Dent 8(3): 376-388.

2. Heymann HO, Hershey HG (1985) Use of composite resin for restorative and orthodontic correction of anterior interdental spacing. J Prosthet Dent 53(6): 766-771.

3. Mangani F, Cerutti A, Putignano A, Bollero R, Madini L (2007) Clinical approach to anterior adhesive restorations using resin composite veneers. Eur J Esthet Dent 2(2): 188-209.

4. Hemmings WK, Darbar UR, Vaughan S (2000) Tooth wear treated with direct composite restorations at an increased vertical dimension: results at 30 months. J Prosthet Dent 83(3): 287-293.

5. Wilson NHF, Mjor IA (2000) The teaching of Class I and Class II direct composite restorations in European dental schools. J Dent 28(1): 15-21.

6. Ferracane JL (2011) Resin composite-state of the art. Dent Mater 27(1): 29-38.

7. Peumans M, Van Meerbeek B, Lambrechts P, Vanherle $\mathrm{G}$ (2000) Porcelain veneers: a review of the literature. J Dent 28(3): 163-177.

8. Zorba YO, Ercan E (2008) Direkt uygulanan kompozit laminate veneerlerin klinik değerlendirilmeleri: iki olgu sunumu. SÜ Dişhek Fak Der 17: 130-135.

9. Hickel R, Heidemann D, Staehle HJ, Minnig P, Wilson NHF (2004) Direct composite restorations extended use in anterior and posterior situations. Clin Oral Invest 8(2): 43-44.

10. Tuncer D, Yazici A, Ozgunaltay G, Dayangac B (2013) Clinical evaluation of diff erent adhesives used in the restoration of non-carious cervical lesions: 24-month results. Aust Dent J 58(1): 94-100.

11. Kopperud SE, Tveit AB, Gaarden T, Sandvik L, Espelid I (2012) Longevity of posterior dental restorations and reasons for failure. Eur J Oral Sci 120: 539-548.

12. Garoushi S, Lassila L, Hatem M, Shembesh M, Baady L et al. (2013) Influence of staining solutions and whitening procedures on discoloration of hybrid composite resins. Acta Odontol Scand 71(1): 144-150.

13. Jones L (2007) The art of matching select porcelain restorations to the anterior teeth: Accreditation case 


\section{Open Access Journal of Dental Sciences}

type II (one or two indirect restorations)-managing contextual colour variances. AACD Journal of cosmetic dentistry 23(3): 38-41.

14. Magne P, Belser U (2002) Bonded Porcelain Restorations in the Anterior Dentition: A Biomimetic Approach Quintessence Pub. Hanover, IL.

15. Asbia S, Saafi J (2017) Smile design (Review). African journal of dentistry and implantology $\mathrm{N}^{\circ}$ 9: 11-28.

16. Raigrodski AJ (2003) Clinical and laboratory considerations for the use of CAD/CAM Y-TZP-based restorations. Pract Proced Aesthet Dent 15(6): 469476.

17. Gandhi KN, Sabita RM, Shah MP (2016) Rejuvenating smile with all ceramic crowns. J Contemp Dent 6(1): 80-84.

18. Layton DM, Walton TR (2012) The up to 21-year clinical outcome and survival of feldspathic porcelain veneers: accounting for clustering. Int J Prosthodont 25(6): 604-612.

19. Layton D, Walton $\mathrm{T}$ (2007) An up to 16-year prospective study of 304 porcelain veneers. Int J Prosthodont 20(4): 389-396.

20. Peumans M, De Munck J, Fieuws S, Lambrechts $P$, Vanherle G, et al. (2004) A prospective ten-year clinical trial of porcelain veneers. J Adhes Dent 6(1): 65-76.

21. Jordan RE (1993) Mosby-Year book, Inc: Esthetic Composite Bonding Techniques and Materials, $2^{\text {nd }}$ (Edn.), St. Louis, 84-6,132-4,140,150.
22. Nedeljkovic I, Teughels W, De Munck J, Van Meerbeek B, Van Landuyt KL (2015) Is secondary caries with composites a material-based problem? Dent Mater 31(11): 247-277.

23. Denbesten P, Li W (2011) Chronic fluoride toxicity: dental fluorosis. Monogr Oral Sci 22: 81-96.

24. Akoglu Vanlıglu B, Kulak Ozkan Y (2014) Minimally invasive veneers: current state of the art. Clin Cosmet Investig Dent 6: 101-107.

25. Goldstein RE, Haywood VB (1998) Principles, Communications, Treatment Methods. In: Goldstein RE (Eds.), Esthetics in Dentistry, 2 ${ }^{\text {nd }}$ (Edn.), BC Decker; Hamilton, Ontario, 1: 14.

26. Ermis RB, De Munck J, Cardoso MV, Coutinho E, Van Landuyt KL, et al. (2007) Bonding to ground versus unground enamel in fluorosed teeth. Dent Mater 23(10): 1250-1255.

27. Weerasinghe DS, Nikaido $\mathrm{T}$, Wettasinghe KA, Abayakoon JB, Tagami J (2005) Micro-shear bond strength and morphological analysis of a self-etching primer adhesive system to fluorosed enamel. J Dent 33(5): 419-426.

28. Gallegos I, Zavala-Alonso V, Patino-Marin N, MartinezCastanon GA, Anusavice K, et al. (2012) Enamel roughness and depth profile after phosphoric acid etching of healthy and fluorotic enamel. Aust Dent J 57(2): 151-156.

29. Rtugrul F, Turkun M, Turkun LS, Toman M, Cal E (2009) Bond strength of different dentin bonding systems to fluorotic enamel. J Adhes Dent 11(4): 299303. 